\title{
ADVANCING IN EMPLOYMENT: THE WAY FORWARD FOR VOCATIONAL REHABILITATION
}

\author{
Grant Duncan*
}

While the Injury Prevention, Rehabilitation, and Compensation Act 2001 re-establishes the ACC scheme on firmer foundations, there are still unanswered questions regarding the rights of individuals with permanent partial disability involving an incapacity for their previous occupation. While the existing entitlements appear to work well for the majority of injured workers, the basic goals set by legislation for vocational rehabilitation still allow the termination of support to be based upon a capacity for any suitable occupation, regardless of the availability of actual employment. No regard needs be given to claimants' long-term skill development or earning potential, let alone to their aspirations to advance themselves in employment. We do not yet fully understand what effect the present vocational rehabilitation provisions are having on claimants' incomes and sustainable employment. In a policy environment that stresses the need for a high-skill, high-productivity economy, and that seeks not to widen social inequalities, the present rehabilitation goals seem inconsistent. Further, it will be shown that they do not meet International Labour Organisation (ILO) standards.

\section{INTRODUCTION}

The Injury Prevention, Rehabilitation, and Compensation Act 2001 (IPRC Act) successfully reestablishes the ACC scheme within its state monopoly model guided largely by the Woodhouse principles. ${ }^{1}$ One of those principles is "complete rehabilitation". ${ }^{2}$ Woodhouse maintained that, in the proposed compensation authority, the needs of rehabilitation should never be overshadowed by administration and costs of compensation benefits. The injured person should be assisted in returning to levels of productivity and independence as close as possible to those enjoyed before the

* Senior Lecturer, Social Policy, Massey University (Albany).

1 Royal Commission of Inquiry Compensation for Personal Injury in New Zealand (Government Printer, Wellington, 1967) [Woodhouse Report].

2 Woodhouse Report, above n 1, 40. 
injury. How well does the present legislation live up to these principles in the context of today's labour market? And what improvements might be needed in the future? The main focus of this analysis will be on how effectively the IPRC Act caters for permanent partial disability, particularly in those cases where a return to one's previous occupation is no longer feasible due to permanent impairment, but where there is nonetheless a capacity for full-time work.

The IPRC Act has removed the strict "hierarchy of considerations" of the Accident Insurance Act 1998 (the 1998 Act) that mapped out a very narrow corridor of options for vocational rehabilitation. ${ }^{3}$ If the claimant could not return to the previous employer or the same occupation, the objective would be to achieve a capacity for any occupation for which the claimant was suited as a result of education, training and/or experience, no matter how low-skilled or poorly-paid, and regardless of the availability of work in that new occupation. Furthermore, the 1998 Act had insisted that all vocational rehabilitation must be of no more than three years' duration and be costeffective. ${ }^{4}$ This gave the priority to the balance sheet over rehabilitation goals and allowed workinjury insurers to lower the standard of rehabilitation outcomes. There was no requirement that vocational rehabilitation restore the worker to an occupational status as close as possible to that which they had achieved prior to the injury. Experience rating, introduced in $1992,{ }^{5}$ and the risk analyses conducted by private insurers under the 1998 Act, created disincentives for the hiring of any new job applicant with a disability or with any lengthy ACC history because of the potential costs of re-injury.

\section{THE INJURY PREVENTION, REHABILITATION, AND COMPENSATION ACT 2001}

The IPRC Act is an improvement on this and I will outline its vocational rehabilitation principles. However, it still does not fully live up to Woodhouse's principles, as I read them - and, more significantly, it does not comply with the International Labour Organisation's Vocational Rehabilitation and Employment (Disabled Persons) Convention 1983 (Convention 159), to which New Zealand is considering becoming a signatory. ${ }^{6}$

Section 80 of the IPRC Act states the purpose of vocational rehabilitation. Paraphrasing that section, its purpose is to help a claimant, as appropriate, to maintain or obtain employment, or regain or acquire vocational independence. This allows for a range of possible situations where, for instance, a claimant may simply want to return to a previous job, may need to retrain for a new

3 Accident Insurance Act 1998, 1st sch, cl 55.

4 Accident Insurance Act 1998, 1st sch, cl 56

5 Accident Rehabilitation and Compensation Insurance Act 1992, s 104.

6 Minister for Disability Issues The New Zealand Disability Strategy: Making a World of Difference (Ministry of Health, Wellington, 2001) Objective 4.7. 
occupation, or may not have been employed at all at the time of injury and so may need to acquire job skills. Section 80 of the IPRC Act also requires that vocational rehabilitation must provide activities leading to employment of a kind that is "suitable for the claimant; and appropriate for the claimant's levels of training and experience."

Nonetheless, the Accident Compensation Corporation has the powers, following the completion of a vocational rehabilitation plan, to determine a claimant's "vocational independence", or capacity for full-time work for which the claimant "is suited by reason of experience, education or training, or any combination of those things". ${ }^{7}$ The assessment of vocational independence is done in two parts: an occupational assessment and a medical assessment. The occupational assessor reports to ACC on the claimant's work experience, education, training, work-skills, rehabilitation outcomes and on "all types of work reasonably identified as suitable for the claimant". 8 The medical assessor then conducts a clinical examination of the claimant and provides an "opinion of the claimant's vocational independence in relation to each of the types of work identified in the occupational assessor's report". 9 Having required the claimant to undergo this assessment, the Corporation may then determine that the claimant, if they have vocational independence, no longer has an incapacity for employment, ${ }^{10}$ and the claimant then loses entitlement to weekly compensation with three months' notice. ${ }^{11}$

I have examined such work-capacity assessments elsewhere, ${ }^{12}$ and will not do so again here. I merely wish to point out for the time being that, while the IPRC Act does state that the goal of rehabilitation is "to assist in restoring the claimant's health, independence, and participation to the maximum extent practicable", ${ }^{13}$ this entitlement is qualified and limited by the extent of the provisions of the Act itself. And the determination of vocational independence creates the possibility that those with permanent partial disability who cannot return to their previous occupation may be exited from the scheme, on the basis of a capacity to be employed in an occupation of a lower status and lower income than that enjoyed previously - regardless of the availability of any actual job in that new occupation. There is no compensation for long-term loss of earnings, no statutory requirement to retrain the claimant in an occupation of a similar social and economic status, and no follow-up to evaluate the claimant's subsequent employment or income.

7 Injury Prevention, Rehabilitation, and Compensation Act 2001, s 6.

8 Injury Prevention, Rehabilitation, and Compensation Act 2001, 1st sch, cl 26(1)(g).

9 Injury Prevention, Rehabilitation, and Compensation Act 2001, 1st sch, cl 29(1)(d).

10 Injury Prevention, Rehabilitation, and Compensation Act 2001, s 111.

11 Injury Prevention, Rehabilitation, and Compensation Act 2001, s 112.

12 See Grant Duncan "The Assessment of Residual Capacity for Work: Easier Said than Done" (1999) 12 Social Policy J NZ 35; Grant Duncan "Moral Hazard and Medical Assessment" (2003) 34 VUWLR 433.

13 Injury Prevention, Rehabilitation, and Compensation Act 2001, s 70. 
Does this shift the burden of the costs of permanent partial disability unreasonably onto the claimant?

Before addressing this question directly, I will survey how much we actually know about the extent, the costs and the consequences of this problem, and consider some developments in related areas of policy that may show us some principles for the future if we were to take a progressive, whole-of-government approach.

\section{RETURN-TO-WORK OUTCOMES}

The data available on workers' compensation schemes throughout Australasia suggests that ACC has the lowest premiums, relatively low rates of compensated work injuries (though compensated work fatality rates are above the Australasian average), and good return-to-work rates, implying that the New Zealand scheme is comparatively cost-effective for employers. ${ }^{14}$ In addition, ACC has made considerable progress since 1996 in reducing the numbers of claims entering the long-term "tail", often by the application of the work-capacity test. Numbers receiving weekly compensation for lost income for more than 12 months halved over the five years to mid-2002 - though this reduction levelled out during the 2002-03 fiscal year. Similarly, the unfunded liability has been reduced by more than half. ${ }^{15}$

"Return-to-work" rates and outcomes for injured workers in New Zealand are now surveyed regularly. ${ }^{16}$ The population in this survey includes injured workers who have received paid compensation for ten days or more and the surveys are conducted six to eight months after the claim was lodged. Eighty-five per cent of this sample had achieved a "durable return to work" - that is, they had returned to work and were still at work at the time of the interview. This compares very favourably with Australian rates (73 per cent). However, 6 per cent had made a non-durable attempt to return to work, and 9 per cent had not returned to work at all.

Of those who had not returned to work at the time of the survey, more than half ( 58 per cent) reported that they had not been able to do so because they were still injured or the injury had become worse or been aggravated. Twelve per cent cited being dismissed by their employer as a reason. ${ }^{17}$

14 Workplace Relations Ministers' Councils Comparative Performance Monitoring, Fourth Report: Australian and New Zealand Occupational Health and Safety and Workers' Compensation Schemes (Commonwealth of Australia, Canberra, 2002); Campbell Research and Consulting Return to Work Monitor in New Zealand 2001/03 (Report prepared for ACC and the Department of Labour, Wellington, 2003).

15 Accident Compensation Corporation Annual Report (Accident Compensation Corporation, Wellington, 2002); Accident Compensation Corporation Annual Report (Accident Compensation Corporation, Wellington, 2003).

16 Campbell Research and Consulting, above $\mathrm{n} 14$

17 Campbell Research and Consulting, above n 14. 
The return-to-work survey does not tell us exactly how many injured workers are returning to work in occupations that are lower-skilled and/or lower-paid than their previous employment - the main concern of this paper. Nonetheless, it does show that, of those injured workers who did return to work, 71 per cent were with the same employer performing the same duties, seven per cent were with the same employer but were performing different duties, seven per cent were with a different employer but were performing the same duties, and, most significantly for the present theme, 15 per cent were with a different employer and were performing different duties. ${ }^{18}$ Different duties, however, could constitute a significant change in occupation or simply a shift to lighter work in the same occupation. We cannot tell from this what percentage of those who returned to work had found themselves in lower-skilled and/or lower-paid employment due to permanent partial disability, but it does indicate that a significant minority of injured workers are having to change employer and/or employment duties as a result of injury.

A number of long-term claims are attributable to those who could find work, but can no longer safely perform the occupations they performed prior to injury - but regrettably ACC inform me that their data does not yet capture information on the subsequent employment of those whose claims they have terminated. This means that it is impossible to say how many claimants have changed occupation as a result of injury.

Only recently has there been research done to estimate how many cases of permanent partial disability exit ACC due to their having a capacity for work, and then transfer onto sickness or invalids' benefits. ${ }^{19}$ About 12 per cent of long-term claimants whose weekly compensation is terminated by means of the work-capacity test transfer to sickness or invalids' benefits within three months. Many of those who do transfer from ACC to such health-related benefits may, of course, do so because of illness or impairment that is not related to the injuries covered previously by ACC. A further 10 per cent go on to receive non-health-related, working-age benefits (for example, unemployment, domestic purposes), and these people are thought to be eligible due to labour-market or personal issues rather than incapacity. ${ }^{20}$

What the compensation authority's data counts as return-to-work or rehabilitation outcomes are mostly only measures of claims terminations, and hence more sophisticated outcome surveys are required. We do not know the extent to which the compensation scheme may be permitting the downgrading of skill-levels and incomes of those who are unable to return to a previous job or occupation. To what extent, in other words, do the rehabilitation entitlements make social and economic inequalities worse? We cannot at this stage measure the extent to which the long-term costs of injury-related incapacity are being transferred on to the injured worker due to inadequately

18 Campbell Research and Consulting, above $\mathrm{n} 14$.

19 Unpublished Data-Exchange Survey conducted by ACC and the Ministry of Social Development.

20 Unpublished Data-Exchange survey, above n 19. 
defined rights based upon short-term, fiscally-defined understandings of cost-effectiveness or workreadiness over-riding any commitment to genuinely suitable and sustainable employment for the injured worker.

\section{COST OF INJURY}

Fortunately, ACC and the Department of Labour are showing an interest in the costs and consequences of injury for the economy as well as for individual injured workers. The Aftermath study ${ }^{21}$ has highlighted the complex, real-life consequences of injuries for the injured person, the family and the workplace, as well as estimating the impact on the whole economy. Furthermore it is likely, given developments in income and employment data, that we may one day be able to track the incomes and employment of injury victims before and after their entry into the ACC system. A link between ACC and IRD data will help in estimating the reductions in incomes experienced by individuals and thus to estimate these indirect costs of injury. ${ }^{22}$ Initial data show that those who have longer spells on weekly compensation experience lower rates of employment, higher rates of reliance on benefits, and lower incomes 6 to 12 months after the termination of ACC support.

The Department of Labour is co-ordinating a "Cost of Injury" project in order to quantify the costs of injury, including lost earnings. A "Return to Sustainable Employment Monitor" has also been proposed in order to improve the information on labour-market outcomes for injured workers.

For the time being though, our knowledge of the overall economic and occupational consequences of permanent partial disability is very limited. ACC has tended in the past not to follow-up the "rehabilitated" claimant after the termination of weekly compensation. Hence, we do not know how they fare after their period of support by ACC. What happens to those who must find a new job or a new occupation? How many are left worse off by that experience? How many, out of desperation, go back to occupations for which they were considered medically unfit, thereby risking re-injury?

These questions about the costs and consequences of personal injury remain to be fully investigated. At least the Aftermath report exists as an excellent qualitative study recording the consequences of personal injury for a small sample of individuals. It raises questions about the kind of support that New Zealanders would expect when such misfortune occurs, and about the relative responsibilities of the individual and of ACC as a social-insurance scheme.

The injured worker is a person who may contribute to society by supporting a family, by working in the community and by being an economically productive employee. Each person is an

21 M Adams and others Aftermath: The Social and Economic Consequences of Workplace Injury and Illness (Department of Labour and Accident Compensation Corporation, Wellington, 2002).

22 M Goodchild, K Sanderson and G Nana Measuring the Total Cost of Injury in New Zealand: A Review of Alternative Cost Methodologies (Business and Economic Research Ltd, Wellington, 2002). 
asset to our society and we should strive to ensure that personal injury results in as little disruption to the injured person's contribution as is practically possible. This, I believe, is the vision that Woodhouse created for us in 1967 under the principle of "complete rehabilitation". ${ }^{23}$ Admittedly Woodhouse was writing at a time of full employment when workers were covered by terms and conditions of employment in national awards. The labour market has changed dramatically since then, and the prospects for most workers, no matter how fit or unfit for work, have become less secure. The attitude of some may be that an injured employee incapacitated and unable to return to a previous job can easily be replaced by a presently unemployed person who is fit for work. But with the increasing demand for and shortage of skilled labour, this view makes little sense. Moreover, viewing incapacity for work as simply a short-term frictional cost for the employer overlooks the long-term losses to productivity and well-being that are borne by the injured person, the family and the wider community.

\section{THE POLICY ENVIRONMENT}

The way forward from today can be guided by principles set out in parallel strategies being developed by the present Government and in Convention 159.

In future, co-ordinated governmental and community actions regarding injuries will fall under the umbrella of the New Zealand Injury Prevention Strategy. ${ }^{24}$ Relevant to my present theme is the Strategy's principle of equity: "injury prevention activity will aim to reduce inequalities in injury outcomes within and between groups." 25 Similarly, the Ministry of Health has recently issued some excellent research and analysis on inequalities in health. A recent document summarises this analysis and proposes an intervention framework that includes minimising the impact of disability and illness on socioeconomic position. ${ }^{26}$ It advises that health services, including accident compensation, "have an important role to play in minimising the likelihood that poor health will adversely affect people's education and employment opportunities", and that best practice would require that interventions should "not make inequalities worse". 27

The Tertiary Education Strategy currently being implemented, speaks strongly of improving the skills of all working New Zealanders on a life-long basis and of equity of access to further education, in particular for people facing barriers, such as those with disabilities. ${ }^{28}$ The wider

23 Woodhouse Report, above n 1, 40.

24 Hon R Dyson New Zealand Injury Prevention Strategy (Accident Compensation Corporation, Wellington, 2003).

25 Dyson, above n 24, 10.

26 Ministry of Health Reducing Inequalities in Health (Ministry of Health, Wellington, 2002).

27 Ministry of Health, above n 26, 22-23.

28 Office of the Associate Minister of Education (Tertiary Education) Tertiary Education Strategy 2002/07 (Ministry of Education, Wellington, 2002) 
imperative is to take a broad approach to the development of the skills necessary for the so-called "knowledge society".

In the Disability Strategy, there is a strong push for the removal of barriers that confront people who are affected by an impairment, and to create a more inclusive society that promotes full participation by all disabled persons. ${ }^{29}$ Objective Four of the Disability Strategy deals with training, employment and economic development, and lays out a wide range of development goals and rights. It is especially interesting that it hints at the possibility of ratifying Convention 159. If compliance with Convention 159 is to be a goal, it is worthwhile looking at that Convention's basic principles.

Convention 159 requires that each Member State "shall consider the purpose of vocational rehabilitation as being to enable a disabled person to secure, retain and advance in suitable employment and thereby to further such person's integration or reintegration into society". ${ }^{30}$

I do not wish to make any criticism of the Accident Compensation Corporation, nor to question the extent to which it is achieving satisfactory vocational rehabilitation outcomes for most claimants at present. The wording of the present legislation guiding ACC's activities in this regard, however, would need to be revised if compliance with Convention 159 were considered desirable by the Government. At present, the IPRC Act focuses on returning injured workers to the same or similar employment as before, and this is unquestionably the simplest and most suitable goal for the majority of cases. Where permanent partial disability makes this result impracticable, however, the IPRC Act gives ACC a much lower standard of achievement: the worker may simply complete a rehabilitation plan and, provided a capacity for some suitable employment is reached, support may be terminated with no further input or follow-up. No further effort need be made to enable the claimant to secure employment - let alone to advance in employment. In fact the result could sometimes be a de-skilling of the worker and a long-term loss of potential income compared to their previous status and prospects.

It is not correct to suggest that this proposal would burden ACC with demands to put all longterm claimants through medical school or something similar. I have already heard from ACC the well-worn story about the injured bee-keeper who wanted to become a university lecturer and I hope that this kind of red herring can be put away. Nor should it be concluded that I am proposing any return to the issuing of permanent pensions - a provision that may be impractical in the absence of national awards and which in the past was too often misused. I am not suggesting either that ACC be required to maintain those with permanent partial disability, who may otherwise have a capacity for full-time work, on 80 per cent of previous earnings for two years or more while they retrain at polytechnics.

29 Minister for Disability Issues, above n 6, 2.

30 Vocational Rehabilitation and Employment (Disabled Persons) Convention 1983 (20 June 1983) C 159, art 1.2 . 


\section{CONCLUSION}

Future refinements of the IPRC Act could include a flexible framework for developing mutually planned arrangements with long-term claimants whereby retraining in a new occupation at a skilllevel and status similar to that enjoyed prior to injury is feasible, even if a capacity for some kind of full-time work may have been achieved. The IPRC Act should not allow for downgrading of people's skills and occupational aspirations. It should encourage the injured worker to "advance in suitable employment." The exact kinds of financial entitlements, rehabilitation support and service provision implied by this proposition should arise from public consultation.

Not only would such improved provisions bring the IPRC Act closer to compliance with Convention 159 - and thus make ratification more meaningful - it would also be more consistent with other public-policy strategies in health and disability services and in education and training. The aim of the Labour-led Government appears to be to reduce social and economic inequalities - at least not to exacerbate them - and to lead the country towards a more high-skilled, innovative and prosperous economy. The IPRC Act needs to play its part in that strategy.

The public of New Zealand needs to be engaged in a consensus-making process about the objectives of their personal-injury social-insurance scheme, and about the levels of cover with which they feel comfortable and for which they would be willing to pay. The basic insurance question I have posed concerns the difference between cover for loss of capacity to perform one's own occupation (or similar occupation) and cover for loss of capacity to perform any occupation for which one may be suited. As a risk that faces all employees, I believe that public consensus should guide our approach to covering the long-term costs of incapacity due to personal injury. And I am confident that most New Zealanders, given the chance to weigh up the risks, would opt for improved entitlements and a higher standard of rehabilitation objectives for those who suffer permanent partial disability involving incapacity for a valued occupation. 
